\title{
Native Storytelling and Narrative Innovation: Louise Erdrich's Love MEdicine as Fictional ETHNOGRAPHY
}

\begin{abstract}
The narrative innovations in Louise Erdrich's Love Medicine, particularly its unique treatment of time and character, are addressed in this study. The narrative investigation serves as a basis for the paper to suggest a new way to read the novel, as a "fictional ethnography". This type of reading shows how the narrative strategy in the novel comments on American Indian history of the twentieth century. In this way the novel shows how narrative devices can be a part of a social and political debate in literature.
\end{abstract}

Key words

Louise Erdrich; Native American literature; Love Medicine; narrative; ethnography

\section{Introduction}

Louise Erdrich's novel Love Medicine (1984, 1993, 2009), ${ }^{1}$ like much of Erdrich's fiction, has met with both critical and popular success. However, the narrative strategies that Erdrich employs in Love Medicine and other novels have not been studied sufficiently, perhaps as a result of the lack of dissent regarding her fiction. Love Medicine is the beginning of an important series of American and Native American novels, and this study takes Love Medicine as an example of Erdrich's fiction. This study focuses on how Love Medicine implements characters and narrators, investigating how the novel adheres to both "popular" (or "traditional") and "literary" genres of fiction, pleasing both sets of readers. Through her use 
of first-person narrators who are also characters in other parts of the book, and more importantly the absence of a conventional main character, Erdrich relies on the limitations of time and place in addition to an efficient implementation of "secondary" characters to both provide coherence to the story and to highlight the content of the story purposefully left out. To better understand Erdrich's innovations in this novel, I propose reading the novel as a "fictional ethnography" that deals with the troubled history between anthropologists and Native Americans (which is outlined below). The novel is thereby also an example of how narrative innovation can also serve social and political ends.

The question that I would like to propose about Love Medicine is how to understand it as a story, when it has no main character and a collapsed hierarchy of characters. In a separate study (Stock, "Louise Erdrich's Place"), I detail the character structure of the novel and show that there is no main character. There are 10-20 important characters in the novel and none of them are a main character; they all seem to be as significant as any other. There is then a lower level of character that demands less attention. Overall the structure seems to violate some of the most basic expectations we have of a narrative or a story. As Catherine Rainwater puts it, "The novel seems rife with narrators, bereft of a focal narrative point of view, and replete with characters whose lives are equally emphasized" (171). Rainwater's more basic point in her analysis is that Love Medicine "frustrates narrativity". This frustration leads to "a textually induced or encoded experience of marginality as the foremost component of the reader's response" and that the marginality comes from "conflicting codes" in the novel: "codes originating within Western-European society and those originating within Native American culture" (164). However, the simple fact that the book succeeds as a popular novel casts doubt on the seriousness of this "frustration" and "marginality", and Rainwater's implicit claim is that Erdrich's innovations are not really narrative innovations but rather a natural result of combining European and Native influences. I find that claim unnecessarily reductive, since the core point that a popular novel is almost by definition not frustrating is rather about narrative strategy than ethnic categories. The novel holds together as a meaningful story for many readers, while still innovating in narrative in a way that literary critics appreciate. Usually we have novels that do one or the other: appeal to the popular reader by relying heavily on convention or implementing innovations (defying conventions) and focusing rather on a specialized, critical reader. How does Love Medicine transgress this division?

\section{A story without a main character}

The fact that this novel is written without a reliance on a central main character already puts it in a rather select group of novels. There are examples of novels without one main character, but they are very few. Those that do not have one main character are self-consciously "experimental" novels, where the lack of one 
main character is a purposeful narrative innovation. For example, several novels associated with the "nouveau roman" school, which purposely de-emphasizes story and plot, also often thereby purposely disregard characters. These novels are valuable, but mostly to the critical world. For obvious reasons, they do not appeal to a wider audience. It is a safe generalization to say that popular novels that appeal to a wider audience do so mainly by following the basic conventions of the novel that have been established and are expected by a large audience. Experimental novels cause the reader to question, very early in the reading of the novel, whether the novel actually contains a story, and/or whether the book can actually be called a novel. In fact, experimental novels seek to bring such questions to the forefront, and their answers to such questions are not clear, even after reading the book (in fact, the questions usually intensify and proliferate). We well know that experimental novels do not seek to meet readers' expectations, and thereby they appeal to less readers. This is a basic transgression of the conventions of reading a novel, which is both a reason for them not to be popular and a motivation for having those innovations in the experimental novel in the first place.

Love Medicine, on the other hand, has been successful with both critical and popular readers: "A best-seller, Love Medicine not only outsold any previous novel by an Indian author, but it also gathered an impressive array of critical awards" (Owens: 2). "Of Erdrich's more than half-dozen novels, the most critically acclaimed is her first, Love Medicine. ... It was received just as enthusiastically by a large international audience" (Wong, "Introduction": 4). Hertha D. Sweet Wong goes on to state that Love Medicine has also succeeded in a realm between the critic and the popular reader: "It continues to be read and taught in literature, composition, women's studies, and Native American studies classes at colleges and universities throughout the United States (and in many other countries as well)" (4). The success in the popular realm already indicates that the novel does contain the "story" that a popular reader expects from a novel. At the same time, the success of the novel in the critical world would suggest that the novel is somehow unconventional.

Therefore, Love Medicine strikes me as unique in transgressing some of the most basic narrative conventions, but still retaining a sense of a story for its readers. To repeat, this unique situation has not been addressed sufficiently in the scholarship. Rainwater's diversion of a narrative study into a study related to social categories is unfortunately typical. My purpose is not to define exactly the path through which the novel reaches these different readers through this unconventional format. This would be a universalizing kind of criticism that seems overly ambitious and ultimately not very useful. Indeed, such a narratology that seeks to find a "grammar of narrative" to which all understandable stories adhere has clearly been an impossible goal for the study of narrative (Stock, "Successes and Failure"). Rather, I would like to take this uniqueness as a starting point to think about what kind of story is in Love Medicine, since presumably that kind of story is unique.

One semantic argument should be diffused at this point. Sometimes Love Medicine is defined as a collection of short stories rather than a "novel". 
Indeed, many of the separate chapters were previously published as short stories, and the self-contained nature of those stories and the chapters in the book lend credence to this interpretation. Hertha D. Sweet Wong claims that in interviews, Louise Erdrich's and Michael Dorris' responses do not seem to form a consistent argument for why the book is called a novel and not a collection of short stories (Louise Erdrich's Love Medicine: 96). The situation seems more ambiguous than Dorris and Erdrich make it out to be, and this is a basis for an interesting analysis of Love Medicine as a "short story cycle" rather than a collection of short stories or a novel. Wong's purpose is "not so much to insist that Love Medicine is a short story cycle rather than a novel, but to consider how it fits into a network of stories" (96). This is not inconsistent with my study. Wong addresses labelling to make a certain point, which is welcome, but we should not derail analyses that do not depend on the exact genre label we assign by worrying too much about what we call the book at hand. Karen Castellucci Cox calls Love Medicine and another example text "novels-in-stories" that are "representative of the story cycle genre" (151). This further shows the close connection and only fine distinction between a novel and a story cycle or collection of short stories.

My view is that such a distinction is only an argument over terms, whereas the useful function of the narrative does not depend on what we call the volume. There are certainly other books that are called collections of short stories that have a large overlap of characters (even having a main character) and the stories seem to be arranged to be taken as a whole, like a novel (Alice Munro's Lives of Girls and Women is one). There are also many other examples of books called novels that have similarly discrete, but linked, chapters that appear like short stories and could be called a "short story collection". In the end, the genre distinction seems to be decided by the author, and is probably more of a marketing distinction than a literary one. Erdrich herself clearly chose for Love Medicine to be presented as a novel, although her reasons for doing so are not clearly stated. I do not find that unclear statement as a fault, but rather indicative of the uselessness of deciding finally on one name or another. In any case, the definition of a novel is certainly flexible enough to include a collection of short stories, so I find little functional difference calling this book one genre or the other.

At the same time, certainly there are books that are more correctly called collections of short stories, especially when there are no important links among the stories. I prefer to think of Love Medicine as a novel because it indicates the purposeful coherence of the text, which, judging from interviews, seems to be Erdrich's intention. At the same time, theory of the novel makes it clear that a novel is not a hermetic whole and does not need to be resolved by a New Critical type of close reading, looking for the unity inherent in the text. That is, seeing it as a novel provides some sense of coherence but not too much.

Moreover, I find the short story-like format of the chapters in Love Medicine to be one of the interesting strategies that Erdrich uses to bridge this critical-popular divide. It is also in line with the lack of one main character. The main character in a typical novel would be the focus of each chapter, and while chapters are made 
to indicate some internal coherence in the content, generally each chapter follows the previous one (thematically or chronologically, and usually both), or the time and events missing between chapters are explicitly deemed dispensable. Without a main character, Love Medicine's chapters focus on specific events that are told by different narrators, and the time and events in between are not so clearly insignificant. In fact, eventually we find out both that there are important events omitted and events that seem less important included. We also get multiple narrations of some events, causing the reader to have to consider what versions to believe.

\section{Time and character(s)}

Love Medicine holds together mainly because of the generally chronological arrangement, the limited time span of the whole story, and the overlap of characters in chapters, rather than having one personage drive the story and be present throughout most of the story. There is no one chapter that does not have characters that are also important in other chapters. At the same time, there is no one character who is present in all or even most of the chapters, even if we use a looser definition of "present", including when characters are not physically present but are a subject of discussion or otherwise influence the story in that chapter. Characters' importance may vary across chapters depending on the specific event being focused on, the narrator, and the time. For example, a character may be in one chapter a small child and in another chapter a grown adult or, similarly, in one place a vital head of a household and in another place a doddering old man. Using the same cast provides the main link among the chapters in the novel.

Indeed, Love Medicine does not have the limitation of a main character, but it does have other limitations. (I do not use "limitation" in a negative sense; all writing necessarily has to use limitations as boundaries to its production and reading.) In the same study mentioned above (Stock, "Louise Erdrich's Place"), I outline a convention of three levels of character in a typical novel: the main character, several secondary characters who are well-rounded because of their relation to the main character, and potentially many third-level characters who are replaceable and/or of only local interest.

Love Medicine does have a hierarchy of characters. What is missing in the typical three-tier hierarchy is only the top: the one main character. Love Medicine still has a small group of "secondary" characters and a larger cast of less important characters. But since the secondary characters are usually defined in relation to the main character, how the secondary characters make meaning in the text is not clear. This small group is one of the tools by which Erdrich retains coherence in her story. Love Medicine is mostly narrated in first person by a character in the novel that is also a character in others' first-person narrations. Several characters narrate in the novel, and there are also parts that use third-person authorial narration. I suggest that, more or less, the group that narrates in first-person in the novel is the group of several "secondary characters". Also the time span of the 
story, 50 years, is a carefully chosen amount of time. It allows for characters to change in a generational way but it is less than a typical life-span. This time limitation is important to the "fictional ethnography" reading I detail below.

These two limitations - a small group of important characters among a larger cast and a carefully chosen time frame - are aspects of the story that Erdrich does not want to hide or obscure. Under the title of each chapter is marked the year when those events take place. Other than prolepses or analepses, this date is always accurate. Further, each chapter or part of a chapter is marked with the name of the first-person narrator. For sections with a third-person narrator, no name is given. After the first few sentences of each first-person-narrated chapter, it is clear that the narration is in the first person, and it is not necessary to interpret (at least the name of) who is speaking to us. The discovery or interpretation of these limits is not what Erdrich wants the reader to be doing with this novel, even though many novels contemporary to Love Medicine have exactly this goal.

Since each chapter is marked by time and character/narrator, one might expect a similar explicit reference to place as well. This does not occur, because the whole story occurs in the same place: one unnamed Indian reservation where there is a convent and a lake with an island in it. The story is further limited by this one place. The only exception is a few events that are narrated that happen in "the city" outside of the reservation, but these are few.

Location is incredibly important for Erdrich herself and for Love Medicine. "Where I Ought to Be: A Writer's Sense of Place" is something of a manifesto stating that while Erdrich has lived in and appreciates other places, the Turtle Mountain reservation of her childhood is her center. This is necessary for her fiction, she feels, and indeed for any writer: "It is difficult to impose a story and a plot on a place. But truly knowing a place provides the link between details and meaning. Location, whether it is to abandon it or draw it sharply, is where we start" (49). The "we" here are "writers". Somewhat paradoxically, the importance of place in Love Medicine, which would fall on the "draw it sharply" axis, means that the place is omnipresent and unchanging and therefore not much worth thinking about as a choice or creation of the writer-artist. Other studies have focused fruitfully on place in Erdrich's fiction, and these studies seek to interpret the organic nature of the fiction, whereas my concern is more to focus on Erdrich's purposeful craft.

The place in Love Medicine is not named, but it is strongly modelled on the Turtle Mountain reservation. Moreover, the characters that occur in this place are strongly modelled on the real-life history of this reservation. In a later novel, Louise Erdrich chooses to name this reservation Little No Horse, so it is fictional. But Julie Maristuen-Rodakowski provides an authoritative and thorough review of how Love Medicine (and the following novel The Beet Queen) is written very much as if it were on the Turtle Mountain reservation. For example, MaristuenRodakowski details the French influence on the tribe and reservation through fur traders from the early days of European contact. Marie Lazarre, shown by her last name, "is most likely a "mixed blood" (16) as presumably is her whole family, 
having ancestors among those original French fur traders. Obviously, Erdrich is either purposefully choosing a French name to indicate this history or naturally using a name like those that she knows from Turtle Mountain.

The characters in the story are also further "limited" in the fact that they all are members of a set of interlinked families: the Kashpaws, the Lazarres, the Lamartines, the Nanapushes, and the Morrisseys. A few characters marry into one of these families and are therefore added to the narration, such as Dot Adare, who marries Gerry Nanapush, or Swede Johnson, who marries Zelda Kashpaw. But these examples are few, and most of the marriages and other relations are within these families. This produces a complicated set of relations, especially since not everyone knows their real parents and sometimes characters are called names like "aunt" or "grandpa" as a term of endearment and/or reflecting a culturally specific non-blood family role, rather than the accurate blood-relation name.

Every novel has a cast of characters, of course, chosen for the purposes of the narration. The way we usually make sense of the constellation of characters in a novel is to gauge each character's importance relative to the main character and/ or the main themes or story that feature the main character. For example, there might be two secondary characters that have nothing to do with each other, but both are important in the story relative to the main character. Since Love Medicine does not have the structure of a main character as such an anchor, Erdrich instead links most of the characters in the story by family ties of one type or another. This includes all the characters in the book, not only the small group of important characters. Again, there are very few exceptions. Andy is the man who picks up June at the beginning of the book and who June leaves asleep in his car as she walks to her death. Andy has no place in any family, and his participation in one of the most important scenes in the book is significant. But the point here is exactly that Andy is not part of the network of family in the book. The point is that June has random sex with an unknown white man in his car and then walks to her death. This event is not supposed to be linked to the family network (for June, Erdrich, or both).

The limitations on character, time, and place provide a kind of coherence to the novel as a whole (to the somewhat separated stories in the chapters of the novel) that "makes up" for the absence of a main character to provide a thread. Obviously, the way that Erdrich sets up the characters in the novel is the most interesting and important facet of the structure of the book, especially in thinking about how it compares to more conventional books that have one main character. With this background of how characters seem to work in this novel, we can now consider the narrative strategy that Edrich employs in Love Medicine.

Above I mention that much of Love Medicine is narrated in first person by a character who is the subject of the narration in other chapters. That is, none of the first-person narrators is only a narrator; all of the first-person narrators are also characters in parts that they do not narrate. However, traditional third-person authorial narration is also used throughout the novel, sometimes for a whole chapter and sometimes for only part of a chapter. But these seem to be exceptions; the 
preferred mode seems to be first-person. Erdrich certainly prefers to write a story in this way: "It is the reason so many stories are written in the first person-I hear the story told" (quoted in Wong, Chavkin, and Chavkin: 112). The third-person chapters are narrated in third person because the events narrated would be difficult to devote to one character. This is for various reasons. Gordie Kashpaw's drinking binge and how he threatens, but is also dependent on, his mother are the topics of "Crown of Thorns" and "Resurrection". Gordie dies later on, it seems that before he dies it would be unlikely that he could narrate such a story, and even if he did, the story would not be coherent. "A Bridge" tells the story of teenager Albertine Johnson going to the city and having sex with Henry Lamartine, Jr. Albertine is a first-person narrator of other parts of the novel, but this seems to be a story she would probably not tell, and Henry dies young. The first part of the book is narrated in third person, because June could not narrate it herself and there are no other witnesses to her death. The use of an authorial third-person narrator seems to be for practical reasons.

Characters in Love Medicine are often defined by what they do, rather than what they say, even though what they "say" constitutes the text of the novel. They do not speak much, and when they do talk, there is a studied avoidance of significant topics. Correspondingly, characters also do not ask about these topics. Perhaps the best example in Love Medicine is the unclear parentage of some of the characters. Some characters do not know their own parents, even though other characters do know. Since people do not talk about it, those who do not know do not find out. For example, throughout most of the novel Lipsha Morrissey does not know who his parents are, having been raised in the Nector-Marie household, although he has suspicions. The novel closes with Lipsha travelling alone in a car with his father, Gerry Nanapush, and the two of them broach the subject of their connection only in coded terms, never explicitly saying to each other that they are father and son. Part of the drama of the end of the novel is that although the reader knows they are father and son, Gerry and Lipsha have not explicitly confirmed this to each other.

Given that characters in the story of Love Medicine ("story" in the narratological sense) are defined by their actions rather than speech, it is particularly unique that the first-person narrators in this novel speak openly about what they know, feel, and have experienced. They narrate in ways that they would never speak aloud. Kathleen M. Sands observes that it "is exactly the inability of the individual narrators to communicate effectively with one another-their compulsion to tell things to the reader, not to each other - that makes their lives and history so very difficult" (40). We can easily see the difference between how characters narrate and how they talk, since all the narrators are also characters in other parts of the novel, so we see both "sides" of the character. A good example is Marie Lazarre. Her narration, like all the first-person narrations, is open and honest, but when she is a character (even in her own narration), she communicates with others in a veiled, coded, deceptive way.

This can be shown in her relationships with her husband and her "favorite" dependent. Marie's husband, Nector, leaves her for another woman and leaves 
a note on the kitchen table explaining himself. When he comes back, chagrined, the note is where he left it, and Marie never tells him whether or not she read it or whether or not she knows what he did. Also, we know about Marie's inexplicable and immediate love for June as a child because she directly explains her feelings in her narration. Marie's own narration of June arriving at her home states, "I didn't want June" (85). But Marie takes her in. "It wasn't long before I would want to hold her against me tighter than any of the others. She was like me, and she was not like me" (87). But as a character, Marie never expresses this to June herself, and when June comes to tell Marie that she is leaving home, Marie reacts as if it did not matter to her. Again, this section is narrated by Marie:

"I want to live with Eli," [June] said in a voice clear as the voice she used to giving directions to be hung. "I'm going to Eli's house."

"Go ahead, then," I said.

I kept peeling the potato. One long spiral and it's finished. I never even looked when she walked out the door. (95)

We therefore get different impressions of Marie from her outward actions in the story and from her narration of part of the story. This is a unique narrative strategy that raises the question on the level of narrative how the first-person narratives can exist at all. This question motivates the idea to compare Love Medicine with written ethnographies.

\section{Reading Love Medicine as a fictional ethnography}

The question about the narrative situation is obviously linked to the general question I am asking in this paper, which is "How is Love Medicine a story?" There are no textual clues that Erdrich gives us to help us construct a vision of how the story is narrated through these first-person narrations.

We could make any number of speculations, such as that each of the chapters is an excerpt from the character's diary or each of the characters are talking to a trusted confidant. None of these or several other explanations have any consistent textual evidence to support it as the best way to understand the way the novel is narrated. There must also be a narrative personality on a higher level than the first-person narrators. This is in general the case since taking Gerard Genette's useful insight into a hierarchy of narrators in any text, some kind of narrator must narrate the third-person authorial parts and also some kind of narrator must gather these narrations from various unrelated narrators to present to use in the form that the novel takes.

I would like to propose one way of understanding this narrative situation that does not claim to be "the" way to understand the narration, but seems useful for thinking through how this is a story and the perspective Erdrich likely takes towards composing the novel. I would like to suggest that this story is told as if 
it were an ethnography. That is, it is a fictional ethnography, which is in at least some ways an oxymoron. Above I cite Erdrich herself saying that she prefers first-person narration because, as Erdrich says, "I hear the story told". This is essentially the same position of a researcher gathering material from oral interviews and translating/transcribing them for consumption by a third-party reader. That is, it is the same position as an ethnographer.

The way I propose to approach Love Medicine is not that it seeks to mimic an ethnographic report. The academic trappings of such a written product are clearly not present nor is the academic context implied. Rather I would like to think of there being a single collector of these stories who filters the stories through his or her own understanding but also tries to accurately represent the stories in the way that they were told to him or her. This collector seems to have engaged in ethnography: "Ethnography is scholarly face-to-face engagement with cultural actors in the domains where they enact and produce culture. Hallmark ethnographic methodologies include participant-observation and ethnographic interviewing" (Kamper: 339). Perhaps this collector engages in participant-observation and that informs the third-person portions of the novel, but more importantly my thought is that this collector mainly engages in ethnographic interviewing and thereby collects the stories to be told in the speaker's first person. It is important, however, not to identify this "ethnographer" with Erdrich and to recognize him or her as another fictional construct within the novel. In some ways, this type of ethnographer might be little more than someone who has heard these stories told around kitchen tables, in living rooms, and at bars, and decides to write them down. That is, calling it an ethnography and situating it within the science of anthropology might be imposing a European-American way of thinking about story-recording on what might be a more natural, family- and relationship-based motivation and understanding. But in the end the coherence and purposefulness of the novel encourage me to think in these more structured terms, while still not being too dogmatic about the comparison.

We must acknowledge, however, that, as Vine Deloria, Jr.'s Custer Died for Your Sins made clear, this method of reading an American Indian text carries with it the burden of the history of anthropological research on American Indians in the late $19^{\text {th }}$ century and early $20^{\text {th }}$ century. During this time mostly white American anthropologists turned to "salvage anthropology" in collecting Native American artifacts. The assumption was that these peoples and cultures are in the last stages of dying out, and therefore evidence of their ways of living should be protected and preserved for future study before they are lost. The problems with this mode of collection are rather obvious. First, the gathering of these artifacts often involved false pretenses if not outright theft, with the righteous anthropologists thinking they were serving a higher purpose and standing in a paternalistic and more civilized position. There was little reason for Native peoples to give up these artifacts; their interest in Western academic study of their peoples was understandably slim. Second, the assumption that these peoples were dying out were clearly false. This was driven by the general cultural attitude that Na- 
tive American peoples are only historical, not to be considered as contemporary members of a community. This attitude is a strange success of the campaign to convince mainstream American society that the American government engaged in genocide against American Indian tribes. That success slipped quickly to the (convenient, opposite) extreme of the completion of that genocide, the absolute extinction of Native peoples and the consequent lack of a need to support that population within American society. Orin Starn describes it this way: "Once Indians had been militarily defeated, a wistful imperial nostalgia took over with many Americans beginning to feel sympathy and pity for the continent's First Peoples" (187). Of course, this timing is not a coincidence. Mainstream America first denied that it was responsible for American Indian genocide and then suddenly accepted this responsibility with regret but also with the assumption that, unfortunately, there are no more Indians left to worry about. It seems that mainstream America still has not found a more realistic way to consider the place of American Indians in contemporary society.

Even more generally, Anna J. Willow claims that "three somewhat overlapping charges infuse indigenous critiques of the discipline [anthropology]". These are: 1. "anthropologists ... presume to "speak for' Indian peoples," 2. "anthropology ... is a deeply colonial project," and 3. anthropology's "fundamental lack of relevance to American Indian communities" (36-38). Willow sees a positive way forward for anthropological study of Native American peoples mainly by correcting the third charge, making research projects more cooperative and directly beneficial to the people they study. This, in some ways, also resolves some of the concerns of the first two charges, and Willow details her own research project within which she tried to study people in a more appropriate way. But the simple fact that Willow is publishing this study in 2010 indicates that such practices have been slow in developing, and Native American suspicion of anthropological research on Native Americans is certainly very alive today and has been since the mid- $20^{\text {th }}$ century. Most American Indians probably agree even today with Deloria's statement that "Indians have been cursed above all other people in history. Indians have anthropologists" (the epigraph to Willow's article, Willow: 33). Willow's call for a new anthropology is not alone, being supported by other studies as well (Kamper, Starn, Beck, Lassiter).

The theft involved in such anthropological research is more obvious (but still contested) when it involves physical items with spiritual significance such as wampum belts or medicine bundles. But the basic principle still held with the gathering of the oral storytelling tradition. The perception was that the people who could tell these stories were dying out, and the stories therefore needed to be recorded for posterity. This reflects the Western perspective on such cultural products, that they are to be written down or otherwise kept in a way that future, unknown people can access in a yet-unknown time and place. The main problem here was that usually American Indian stories are meant to be oral performances to be experienced in real time. They depend on the unique storyteller and storytelling instance; what is recorded is only one instance among many. Further, 
storytelling is a ritual that often followed strict rules regarding who could tell the story, who could attend the telling, what time of year and day it could be told, etc. These are also things that cannot be recorded in a Western understanding, especially in literary studies, which focuses on the written text, with a necessary distance between the writer and reader, as the primary site of the making of meaning.

For oral performances, anthropologists in many instances attended and recorded the telling of stories when they should not have even been present at the event (much less recording them). This was the first transgression, and the second transgression was the representation of these stories in a mode completely foreign to the purposes of these stories: writing. Seminal works like Paul Radin's The Trickster: A Study in American Indian Mythology are excellent examples of researchers who go to great lengths to show how careful they were in recording and communicating these stories. Most often the researchers sought to represent these stories "accurately". The problem is that this is impossible to do without misrepresentation and without disrespecting that story, that storyteller, and that community. This problem is most clearly evident for ceremonial storytelling situations, but also adheres to more traditional interview-based ethnographic research. It was difficult for ethnographers to ethically gain permission from the subjects they study, and it is a concern whether and how ethnographers can gather information from peoples who have no concern for the Western academic tradition of research. Even in standard interviews - where a researcher records answers to questions or non-sacred stories to use for academic research - ethical concerns difficult to resolve.

Later, in the first half of the $20^{\text {th }}$ century, American Indians started realizing the scale on which anthropologists were conducting these activities, and started to speak out against the practices. Starn connects this to the movements to provide different populations more respect and freedom in the 1960s and 1970s in general and the "Red Power" movement in particular (184). This curtailed the practice to a large extent, but by then much damage had been done. Apart from the damage to important physical objects and the due respect to tribal cultures, the damage perhaps more importantly involved Native Americans understandably having a deep-seated mistrust of any kind of academic research on Native Americans. Obviously more mistrust between mainstream America and Native Americans was not welcome at this time. Starting in the 1970s, this situation has improved somewhat with more Native American anthropologists working in the field and advocating using the results of the research to benefit Native populations. But the history of the exploitation of Native Americans by anthropologists and ethnographers remains.

In that historical and cultural context, Louise Erdrich seems to have chosen to write Love Medicine in such a way that it can be read as if it is reported by an ethnographer. This leads to interpretive questions related to the fictional ethics of how these texts come to us as readers that this study will not explore. I am rather concerned at present to propose this type of reading in general and leave it to future research to perhaps debate how such a method might change our view of Love Medicine. 
Above I indicate that classical ethnography includes the researcher coming in face-to-face contact with the people being studied and that typical methods are observation and interviewing. The data gathered by these methods is then processed by the researcher and put into a written form that is understandable and significant to an academic reader in the field.

What I imagine about Love Medicine is that an ethnographer has interviewed (more or less formally) characters in this novel and chosen to represent the data thus collected by writing as if it was the subject writing him or herself. Ethnography is usually done for an academic purpose. However, Love Medicine seems to leave this realistic context of ethnography aside. In my view, the text that we read is understood to be a collaboration between an ethnographer and the character, but the purpose of the ethnographer is to accurately represent what the character has said, but to also represent it in a way that is somewhat consistent in style, scope, and approach with other characters' data so that a reader can understand them all and therefore use them together to form a story. If we follow Gerard Genette's conception of levels of narrators (which I find useful), there is a narrator above this ethnographer, a narrator who "creates" that ethnographer. The ethnographer is then a kind of narrator, but not the highest-level narrator, and is also another character. Again, my purpose is not to polemically state that the novel is "like" an ethnography, but rather to suggest an alternative way to read the novel.

The reading experience of the first-person narrations are remarkably similar given the diversity of personalities of the narrators. They are not the same, but the scope and approach of each are very similar: each one is very honest, each one is self-aware of telling a certain story, each one offers not only information about the story but also about the narrator him or herself and other characters that do not seem necessary to tell the story. Also, at least some of these characters seem very unlikely to want to or be able to tell their own stories in the way they do. These qualities indicate that a singular narrative consciousness is processing these different stories told by different characters, providing consistency in the reading experience but maintaining at least some of the diversity in the stories and personal histories of the "subjects".

The effect is as if one person conducted interviews with the characters and helped them record their stories in a roughly similar way. Not all of the characters themselves would care to tell their stories and most of them likely would not present them in this way themselves. While the ethnographer has an interest in consistency among the texts, $\mathrm{s} /$ he also has an interest in preserving the subject's voice. The narrators in Love Medicine certainly have their own voices: both the style of the text presented and the information communicated seem to fit the characters as we understand them from the novel overall. Lipsha is a good example. The way he tells the story of the "love medicine" that he practiced on Nector, employing a mix of self-aggrandization, humility, and humor, simply rings true compared to the way he appears through other narrators' sections. Also, the interest of the anthropologist would be to accurately represent the words of their subject, rather than coopting those words for his or her own purpose, as a novelist, 
storyteller, or other person who would present a story to an audience might have. This would explain why most of the novel is presented in first person. The interest is to let the characters speak for themselves, helping them as little as possible. The purpose of an ethnography is to gather empirical data from which conclusions can be drawn. In an academic study, the researcher would implement a methodology to come to these conclusions. As a novel, this text does not explicitly draw conclusions from its empirical data: that is the reader's job. It is only a presentation of that data.

Moreover, this also connects with the "short-story-like" character of the novel. Kathleen M. Sands asserts that the novel "is a narrative collage that seems to splice random margins of experience into a patchwork structure" (35). The book is sometimes defined as a short-story collection exactly because of this quality. The chapters are separate from each other, and their internal coherence highlights the discreteness. However, Sands only writes that each chapter "seems" to be randomly chosen. In fact, Sands continues to specify that indeed the chapters, episodes, and scenes in the novel are not randomly chosen. "Yet ultimately it is a novel, a solid, nailed-down, compassionate, and coherent narrative that uses sophisticated techniques toward traditional ends. It is a novel that focuses on spare essentials, those events and moments of understanding that change the course of life forever" (35).

Sands here seems to say that the chapters in the book are in some way the "most important" events. I would be more hesitant. The chapters are certainly chosen and not just random glimpses of lives and relationships, but at the same time I do not think that Erdrich narrates the "greatest hits" of these characters' lives in Love Medicine. Nor does she pick out particular events to craft a particular story. Erdrich's other novels in this series show that Love Medicine is not the complete story. By the third version of the Love Medicine, published in 2009, Erdrich seems to have no more hope that she will ever finish with these characters. In the "Author's Note" of the 2009 version, Erdrich writes, "The characters appear and disappear in my consciousness [...] . I wrote about them as they present themselves. [...] Indeed, they have not finished with me yet" (6). The story to be told here, as an ethnography with such a naturally rich environment, is infinitely long. These chapters are not the "most important" events of these characters' lives, and they also are not chosen to be coherent. An ethnography, too, must select for analysis parts of the data gathered, and the principle guiding this selection has to do with what seems significant. Love Medicine has a different way to tell this kind of "incomplete" story, positioning it as part of a story so large it is impossible to tell completely. The discrete quality of the chapters indicates that there is a plethora of other events, other stories, to tell in between, around, and beside these stories.

The fictional ethnographer, therefore, has an infinite number of stories that s/ he could tell, although this infinity is bounded by the limitations on this book that replace the main-character structure: time, location, and the five families. A real ethnographer typically chooses a location and defined group of people to focus 
on for observation. These two factors inevitably then determine the time span of an ethnography. Presumably the data an ethnographer is interested in gathering is usually about the life of that group of people in that place in the present time. The ethnographer is not primarily interested in recording stories about what people from generations before did or thought. That data would already been secondhand and even more difficult to analyze than the already-filtered data gathered from people themselves about themselves and their lives. This data would be taken rather as a kind of fiction told by the subject and therefore more informative about that subject than those in the past. Older people might tell stories from their youth that might reach back 50 years or so, and any subject can tell contemporary stories.

Love Medicine fits this type of time frame as well, where the fictional ethnographer records Marie's story from 1934 up to Lipsha's story from 1984, and the recording happens sometime after 1984. It is as if the ethnographer were recording the life stories of these interconnected and localized families, and even though there is a limited time and a limited number of people, there is an infinity of stories that one could tell. Love Medicine obviously leaves out many of those stories, although it does clearly present some important stories. There might be other stories that are as important, and we assume that there are other more mundane stories that are less important. In fact, some of the left-out stories we know about through the incomplete narration in the novel itself. June's death is actually not narrated. At the end of the first section of the first chapter we see her walk alone into the Easter-morning snowstorm, and in the sections that follow characters refer to her as already dead. At the end of the novel, Lipsha refuses to tell the story of whether Gerry actually committed the crime for which he has been put in jail. These are events that we know happened, so we know that they are purposefully omitted from the narrative. However, there must be a much larger set of stories (life events) that the ethnographer will not hear about and that will not get told, or that the ethnographer has heard but chooses not to include. A normal story in a normal novel is presumed to be a careful creation of significant events to tell the story. As a fictional ethnography, Love Medicine takes away the assumption that the narrator-author performs this creation/selection, or at least inserts another narrative consciousness into this decision.

Not only are there stories left out (some indicated in the text but most of them intuited as present-but-absent, possible but not narrated), but the first-person narration offers a further possibility of infinity in that different characters narrate different versions of the same story. The death of Henry, Jr. famously has two varying narrations, both of which are presented as equally authentic. Because the novel avoids an authoritative third-person narrative voice, most of the narration in the novel could be re-told by another character in another way. Some of the third-person events could even be re-told in first person, to different effect. Many of the events narrated in Love Medicine could be re-told by other characters.

This is another way that Erdrich crosses boundaries, and another way that she satisfies different readers. The stories that are chosen to appear in the book are 
interesting and told in an interesting way. They are enjoyable even on a casual read. But the method of narration - both the identity of the narrator and the structure of the narrative in the whole novel - to a more critical eye shows us that this story, for all that it seems satisfying and coherent, is only one small piece of an infinitely huge story, all of which and any of which theoretically could be told.

\section{Conclusion}

This paper has sought to first establish that Louise Erdrich's Love Medicine is worthy of deeper study in terms of narrative strategy, and that such study has been lacking in the voluminous criticism on the novel. This is perhaps because it is (somewhat wrongly) not seen as an "experimental" novel, since it appeals to a popular audience. The paper then suggests a new way to read Louise Erdrich's Love Medicine in line with the narrative strategy: as a fictional ethnography. This way of reading the novel uses the innovative narrative strategy to come to interesting conclusions about how the novel implicitly comments on twentieth-century American Indian history.

American Indian Studies has long struggled with the ethics and practicality of both the procedures and results of the work of anthropologists, especially in the early part of the twentieth century. Love Medicine, understood in the way I am proposing, implicitly comments on this debate in a way that dramatizes, but does not resolve, the concerns. The novel can be seen as ironic or the narrative strategy might just be a useful device. Love Medicine focuses on American Indian characters who are almost all mixed-blood. But Erdrich chooses to create an invisible narrator of the type that Henry James popularized early in the century, someone who must be present but does not announce him or herself in any way. This type of narrator is very often equated with the author. This is not correct in my view, but it usually does not make much of a difference in analysis. The narrator of this novel can be seen an ethnographer. His or her purpose is to record, revise, and present the stories of some of the people within the group s/he has chosen to study: the people in these families on this reservation.

The debate about the ethics of such a project hinges on the choice between two paths, neither of which have completely desirable ends. The first path is not to intrude on the local culture at all, to not conduct an ethnographic project. One justification for this choice is that the presence of the observer anyway corrupts the data one would want to collect. In Native American cultures, this concern has been even more extreme when researchers have wanted to record traditional oral storytelling performances that, according to the culture, should not have any foreigners, and often only a subset of the tribe itself, present at the storytelling. One might decide not to record at all either because of ethical concerns with disrespecting the culture or the practical concern that such a method will not collect valid data anyway. The second path is to engage in such a project knowing the 
ethical and practical risks involved, but deciding that even corrupted data and analysis is better than none.

Most often in the study of American Indians over the past 150 years or so, the researcher is a European-American, so the ethical and practical concerns are more extreme. We have many examples, especially from early on, when such researchers clearly crossed ethical boundaries and disrespected tribes in unacceptable ways. Such experiences caused many Indians to feel understandably dismissive of any such research projects. In the end, the goal of such projects was to help mostly European-American readers to better understand these tribal people, which the tribes themselves did not perceive as a need. On the other hand, and especially later on as researchers became more sensitive and developed more ethical techniques, many American Indians also saw a value in having their disappearing tribal traditions recorded in some way. Until the middle of the $20^{\text {th }}$ century, there were still people who grew up and lived in the traditional way and could tell the traditional stories. However, the inevitable effect of the European invasion of the American continent was that Indian people would mix with the larger culture and by today we have come to a time when virtually no people exist who can tell these stories. They have simply died out and new generations have not carried on in the way that they have for uncountable generations. This is not a failure of Native American culture or people, but rather another change and adaptation in their centuries-long history. In addition, the Native American storytelling tradition usually relies on more than one storyteller. The story must be told in a certain time and place, and it must be told to a certain restricted audience (depending on the type of story). The character of the storytelling as a traditional community event, that requires not only one traditional holdout storyteller, but a larger group of such people, made the tradition very difficult to maintain in the $20^{\text {th }}$ century. Much culture has simply been lost. The parts that have been recorded in ways understandable to a European-American culture survive. Some Indians came to value this survival, even though we cannot know if the picture those recordings provide is accurate.

Nancy J. Peterson writes that "Writers like Erdrich thus face a vexing set of issues: unrepresented or misrepresented in traditional historical narratives, they write their own stories of the past only to discover that they must find a new way of making history" (984). E. Shelley Reid posits the dilemma in more challenging terms: "Like many other Native American authors, Erdrich faces a textual and cultural challenge: to reclaim a Native American identity from the Coopers and Disneys of Euro-American cultures, and then find a way to share it with an audience that suspects that she and her culture are on the brink of extinction" (67). These writers show both the importance of and the difficulty with writing American Indian novels in the late $20^{\text {th }}$ century. When reading Love Medicine as a fictional ethnography, we see the narrator not trying to preserve a dying culture, but rather to investigate and document what is in some ways a "normal" life of a "normal" set of people living in a "normal" place. One could imagine such a project being employed for many different groups of people in certain places. 
Again, this novel chooses to focus on these people and this place, but it is not presented as such a unique choice. One of the messages that comes from telling the story in this way is that all of us in human society belong to such groups and participate in creating such stories in our everyday lives, and creating, recreating, telling, and retelling such stories serves both individual purposes as well as a larger cultural preservation and vitalization.

\section{Notes}

Love Medicine has been published in three versions to date. The first version was published in 1984. Love Medicine: New and Expanded Version was published in 1993, and included many significant changes. Critics debate which of these two versions should be used for study. Mostly the debate breaks between those who favor the "original" text as a more authentic object of study and the later version as the more definitive product of careful consideration. I choose to refer to the 1993 text, although the version does not impact this study. In 2009 Erdrich published a third version on the $25^{\text {th }}$ anniversary of the original publication, making some minor changes and moving one chapter from the main text to a "Notes" section at the end of the book (which also includes an author interview and other such resources).

\section{References}

Beck, David R. M. (2010) "Collecting among the Menomini: Cultural Assault in Twentieth-Century Wisconsin”. American Indian Quarterly 34(2), 157-193.

Cox, Karen Castellucci (1998) "Magic and Memory in the Contemporary Story Cycle: Gloria Naylor and Louise Erdrich". College English 60(2), 150-172.

Deloria, Vine, Jr. (1969) Custer Died for Your Sins: An Indian Manifesto. New York: Macmillan.

Erdrich, Louise (2009) “Author's Note". In: Erdrich, Louise Love Medicine: Newly Revised Edition. New York: Henry Holt and Company, 5-6.

Erdrich, Louise (1986) The Beet Queen. New York: Henry Holt and Company.

Erdrich, Louise (1984) Love Medicine. New York: Holt, Rinehart and Winston.

Erdrich, Louise (1993) Love Medicine: New and Expanded Version. New York: HarperCollins.

Erdrich, Louise (2009) Love Medicine: Newly Revised Edition. New York: Henry Holt and Company.

Erdrich, Louise (2000) "Where I Ought to Be: A Writer's Sense of Place". In: Wong, Hertha D. Sweet (ed.) Louise Erdrich's Love Medicine: A Casebook. New York: Oxford University Press, $43-50$.

Genette, Gérard. (1972) Narrative Discourse: An Essay in Method. Trans. Jane E. Lewin. Ithaca: Cornell University Press.

Kamper, David (2005) “American Studies, Ethnography, and Knowledge Production: The Case of American Indian Performers at Knott's Berry Farm". American Studies 46(3-4): 339-361.

Lassiter, Luke Eric (2005) "Collaborative Ethnography and Public Anthropology". Current Anthropology 46(1): 83-106.

Maristuen-Rodakowski, Julie (2000) "The Turtle Mountain Reservation in North Dakota: Its History as Depicted in Louise Erdrich's Love Medicine and The Beet Queen". In: Wong, Hertha D. Sweet (ed.) Louise Erdrich's Love Medicine: A Casebook. New York: Oxford University Press, $13-26$.

Munro, Alice (1971) Lives of Girls and Women. Whitby: McGraw Hill Ryerson Limited. 
Owens, Louis (2000) “Erdrich and Dorris's Mixed-bloods and Multiple Narratives". In: Wong, Hertha D. Sweet (ed.) Louise Erdrich's Love Medicine: A Casebook. New York: Oxford University Press, 53-66.

Peterson, Nancy J. (1994) "History, Postmodernism, and Louise Erdrich's Tracks". PMLA 109(5), 982-994.

Radin, Paul (1956) The Trickster: A Study in American Indian Mythology. New York: Schocken Books.

Rainwater, Catherine (1990) "Reading between Worlds: Narrativity in the Fiction of Louise Erdrich". American Literature 62(3), 405-422.

Reid, E. Shelley (2000) “The Stories We Tell: Louise Erdrich's Identity Narratives". MELUS 25(34), 65-86.

Sands, Kathleen M. (1985) "Love Medicine: Voices and Margins". Studies in American Indian Literatures 9(1), 12-24.

Scholes, Robert (1982) Semiotics and Interpretation. New Haven: Yale University Press.

Silko, Leslie Marmon (1986) "Review of The Beet Queen by Louise Erdrich". Studies in American Indian Literatures 10(4), 177-184.

Starn, Orin (2011) "Here Come the Anthros (Again): The Strange Marriage of Anthropology and Native America". Cultural Anthropology 26(2), 179-204.

Stock, Richard (forthc.) "Louise Erdrich's Place in American Literature: Narrative Innovation in Love Medicine". Prague Journal of English Studies.

Stock, Richard (2013) “The Successes and Failure of Narratology". Narrative Inquiry 23(2), 371387.

Willow, Anna J. (2010) "Cultivating Common Ground: Cultural Revitalization in Anishinaabe and Anthropological Discourse". American Indian Quarterly 34(1), 33-60.

Wong, Hertha D. Sweet, Nancy Feyl Chavkin, and Allan Chavkin (2000) "Interviews with Louise Erdrich and Michael Dorris". In Wong, Hertha D. Sweet (ed.) Louise Erdrich's Love Medicine: A Casebook. New York: Oxford University Press, 155-160.

Wong, Hertha D. Sweet (2000) “Introduction”. In Wong, Hertha D. Sweet (ed.) Louise Erdrich's Love Medicine: A Casebook. New York: Oxford University Press, 3-10.

Richard T. Stock received his Ph.D. from the Department of Anglophone Literatures and Cultures at Charles University in Prague and his M.A. in Literature and Theory from the University of Illinois at Urbana-Champaign. He is currently an Assistant Professor in the English Department at the Faculty of Philosophy at the University of South Bohemia in České Budějovice. His research interests include contemporary and postmodern American literature, the novel, narrative, and Native American literature.

Address: Richard Stock, Ph.D., Department of English, Faculty of Philosophy, University of South Bohemia in České Budějovice, Branišovská 31a, 37005 České Budějovice, Czech Republic. [email: stockr@gmail.com] 
